Article

\title{
Hazard Assessment of Storm Events for the Portuguese Northern Coast
}

\author{
Mariana Peixoto Gomes ${ }^{1}$, Lara Santos ${ }^{1}$, José Luís Pinho ${ }^{1}$ and José S. Antunes do Carmo ${ }^{2, *}$ (D) \\ 1 Department of Civil Engineering, School of Engineering, University of Minho, 4710-057 Braga, Portugal; \\ marianapeixotogomes@gmail.com (M.P.G.); larasantos08@gmail.com (L.S.); jpinho@civil.uminho.pt (J.L.P.) \\ 2 Department of Civil Engineering, FCTUC_Polo II, University of Coimbra, 3030-788 Coimbra, Portugal \\ * Correspondence: jsacarmo@dec.uc.pt; Tel.: +351-239-797-153
}

Received: 30 November 2017; Accepted: 9 May 2018; Published: 14 May 2018

check for updates

\begin{abstract}
Coastal zones currently face severe weaknesses and are subject to high-risk situations. Tropical storm events can contribute to the occurrence of these high-risk situations by causing storm surges with high water levels and, consequently, episodes of wave-overtopping and coastal flooding. This work considers a series of storm scenarios and analyzes their impacts through numerical modeling. Firstly, historical storm tracks and intensities are characterized for the Portuguese northern coast in terms of probability of occurrence. Secondly, several storm events with a high potential of occurrence are generated using a specific tool of the DelftDashboard interface for Delft3D software. Hydrodynamic models are then used to generate an ensemble of simulations to assess the storms' effects on coastal water levels. Based on the statistical data of the numerical modeling results, a synthesis of the coastal storms' impacts at different locations within the study area is performed. Depending on the storm category, surge heights can reach $1.10 \mathrm{~m}$ above tide levels under simulated conditions on the Portuguese northwestern coast.
\end{abstract}

Keywords: coastal zones; storm events; Delft3D; DelftDashboard; numerical modeling

\section{Introduction}

Coastal flooding as a result of storm occurrences causes hazards to property and coastal populations, which are intensified by the increasing occupation of coastal regions over the last decades. These flood events are the most frequent, costly, and deadly dangers that impact coastal communities. Coastal flooding mainly results from storms and storm surges, and can also be aggravated by sea level rise as a result of climate change. Indeed, in the last decade, the successive breaking of high temperature records has been a growing concern at a global level. Climate change has become a high priority global problem [1].

Portugal is a country with a mild Mediterranean climate, and is well known for its vulnerability to climate variability. The mean annual precipitation on Portugal's mainland is around $900 \mathrm{~mm}$, with a very high degree of spatial variation. Average global surface temperatures have increased by approximately $0.6{ }^{\circ} \mathrm{C}$ since the late 19 th century, with $95 \%$ confidence limits of nearly 0.4 and $0.8^{\circ} \mathrm{C}$. Changes in the frequency or intensity of extreme weather, climate weather, and climate events are likely to have notable effects on the environment and consequently on society itself [2].

Downscaling of climate change scenarios for sea level rise assessment should be properly contextualized, since its quantification depends on a great number of complex physical processes including land subsidence changes, eustatic sea-level change, freshwater discharge variations in river deltas, and tidal range alterations [3]. However, for extreme short-term events like coastal storms, whose effects can be aggravated by a sea level rise, once they have become more intense and frequent already constitute a threat for coastal environments. Low lying coastal territories, which usually 
coincide with estuaries and river deltas, are among the most vulnerable coastal areas to the impacts of coastal storms. On the northwestern Portuguese coast we can identify four main estuaries: the Minho, Lima, Cávado, and Douro estuaries [4-6], which have a considerable number of exposed areas that are vulnerable to coastal storm effects (Figure 1).

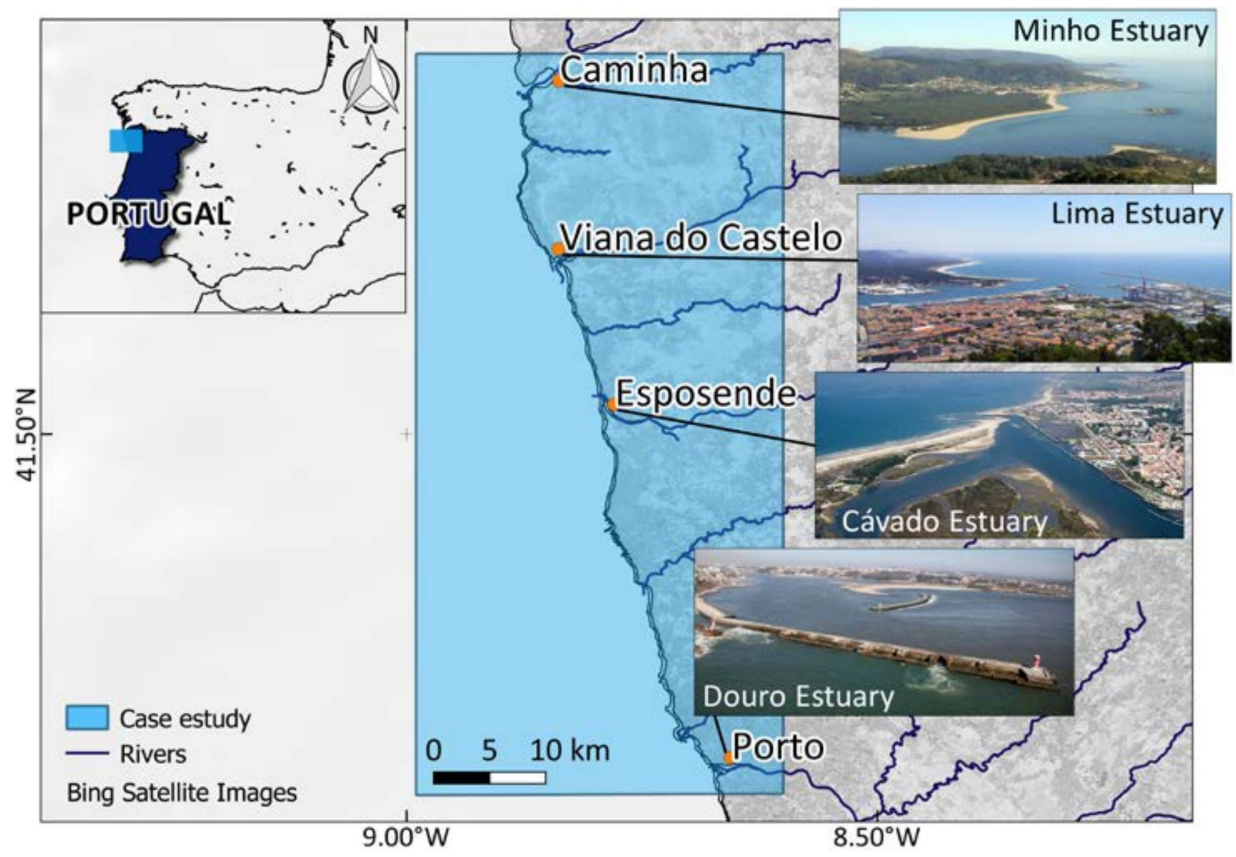

Figure 1. NW Portuguese coast case study location and its main estuaries.

All these estuary embankments are very intensively occupied. The mouths of the Minho and Cavado rivers still maintain a relatively low degree of anthropic modifications. On the contrary, the mouths of the Lima and Douro rivers are defended by breakwaters for navigation purposes.

Besides these four main estuaries which are vulnerable to coastal flooding, the NW coastal segment is composed of other locations that are vulnerable to coastal storms that also coincide with small river mouths. At other stretches the coast is naturally defended by rocky outcrops parallel to the coast to a considerable extent, and more recently by gravel beaches that form a natural barrier between the ocean and the frontal dunes that were suffering from an intensive erosion process before their development [7].

The tides are mesotidal and semidiurnal, with a maximum equinoctial spring tide high-water level of $3.90 \mathrm{~m}$ and a minimum low-water level of $0.20 \mathrm{~m}$ (Portuguese chart datum). The mean spring-tide range is $3.75 \mathrm{~m}$. The wave climate is characterized by a mean significant wave height of $2.12 \mathrm{~m}$ and a period of $9.3 \mathrm{~s}$. The maximum wave height during normal winter storms is $4.11 \mathrm{~m}$. The wave direction is predominantly NW, causing southward longshore drift.

All these coastal locations are vulnerable to weather events, including coastal storms that can induce significant storm surges. According to wind speed statistics observed daily from 7 a.m. to 7 p.m. between November of 2000 and August of 2014, for the region of the Douro estuary, the highest recorded values were, on average, between 14.82 and $16.67 \mathrm{~km} / \mathrm{h}$ [8]. These values are of little importance in terms of storm surges. The importance lies in the swells created by wind speeds observed farther off the coast of Portugal.

During the winter, the Portuguese coast is affected by a heavy swell about $30 \%$ of the time, extending to about $20^{\circ} \mathrm{W}$ [9]. The wave energies produced by tropical storms occurring far from the Portuguese coast are not distributed evenly along its significant width at the fetch exit region. As a wave train leaves the fetch, it may leave at an angle to the main direction, thus arriving at a forecast point but lying to one side of the wind direction. Maximum wave heights will occur along 
the centerline of the fetch. The result is that the greatest swelling impact will occur where the large circle path of the fetch centerline intersects the final destination. Due to angular spreading, the swell radiating from the fetch centerline can have a wide impact [10]. This is the case for many of the systems that affect the Portuguese coast. Because this extremity of the Northern Atlantic Basin usually gets hit with the tail-end of tropical systems, it is very frequent that their impact is more due to swells than the actual strike of the storm against the shoreline.

According to research done by the Centre for Climate Adaptation (CCA) [11], an increase in severe storms of prevailing tropic origin reaching Western Europe is anticipated as a result of 21st century climate change. An extended eastward extension of tropical storm development is projected. Tropical cyclones typically move in a north-westerly direction, originating in the tropical Atlantic and catching predominately westerly winds. This wind veers its track in a north-easterly direction, with the possibility of reaching Western Europe. If the cyclone's genesis in the tropical Atlantic is further to the east, the possibility of it reaching Western Europe increases. In addition, a resulting shorter distance traveled can allow for the tropical characteristics of hurricanes to be maintained, with less time available for dissipation to occur [12]. With the aid of model simulations, one can conclude that the consequences of such occurrences can have truly disastrous effects. With the projected rise in sea surface temperature, the frequency of severe winds and a resulting shift in the projected season of storm occurrences could be observed.

The main purpose of this paper is to study storm occurrences on the Portuguese northern coast, explore the characteristics and pathways of the tropical storms that affect the area, and most importantly, with the aid of hydrodynamic models, evaluate the vulnerability of the coast to storm surges. The variation of storm surge heights depends on numerous factors such as the tropical storm category, forward speed, radius of maximum speed, proximity of the storm trajectory to the coastal zone, bathymetry, coastal geomorphology, and shape of coastline [13]. As a result, numerical modeling systems are essential for a detailed forecast of the possible impacts of coastal storms. The methodology of the design of hypothetical scenarios resulting from geographical shifts of the registered historical tropical systems is presented. The main results obtained for different locations are also shown.

\section{Material and Methods}

\subsection{Hydrodynamic Software and Storm Winds}

The same methodology presented in research from Gomes et al. [14] was applied. In the first phase, data on the historical coastal storms that occurred near the Portuguese coast were collected using the National Oceanic and Atmospheric Administration [15] and Unisys Weather [16] databases as well as the University of Hawaii Sea Level Center's database. DelftDashboard Version 2.01 (Deltares: Delft, The Netherlands) and Delft3D-FLOW Version 4.03 (Deltares: Delft, The Netherlands) $[17,18]$ were applied for the assessment of the effect of storms on the surface elevation of the water along the Portuguese northern coast. With the aid of the DelftDashboard software a grid was generated, and the corresponding open boundary conditions were defined. The wind field associated with the storm trajectory was also generated with the aid of the DelftDashboard tools.

The second phase was focused on the simulation of scenarios using a numerical model for the different trajectories and intensities of the collected historical storms. A very fine grid was adopted, covering an area extensive enough so that the region of the northwestern Portuguese coast would be clearly distinguished and the area under analysis would be far away enough from the open boundaries to minimize the impact of inconsistencies resulting from the conditions adopted at those locations. Because there are no available data for northern Portuguese observation stations, the application of DelftDashboard's Tropical Cyclone Toolbox to this region did not allow for a detailed comparison of the predicted results to the actual observed results. However, the obtained simulated results are of the same order of magnitude as the results found in the literature. 
The hydrodynamic numerical software, Delft3D-FLOW [17] considers different physical phenomena such as the Coriolis force, water density gradients, tidal flow analysis, currents induced by wind, and pressure gradients. Pre-processing tasks were supported by the above-mentioned tool, DelftDashboard. This tool allows for the definition of the model grid, its bathymetry, the open boundary conditions, and the generation of the wind field $[17,18]$ associated with each simulated storm.

Delft3D solves the nonlinear shallow water equations in two and three dimensions. These equations are derived by averaging the full Navier-Stokes equations in the vertical direction, assuming that the horizontal scale is much larger than the vertical. The vertical accelerations are assumed to be much smaller than the horizontal ones, which reduces the vertical momentum equation to a hydrostatic pressure equation. For a three-dimensional shallow water model, the flow domain is made up of a horizontal plane of a limited area composed of open and closed boundaries, and in the vertical direction a number of layers are defined. The model's hydrodynamic formulation details are presented in the paper by Gomes et al. [14]. It uses the alternating direction implicit (ADI) method to integrate shallow water equations in time. The ADI method splits a single time step into two phases, in which each phase makes up half of a time step. In both phases, all terms of the model equations are solved in a consistent way with at least second order accuracy in space [17]. It also uses three different spatial discretizations (in terms of advection): the WAQUA-Scheme, the Cyclic Method, and the Flooding Scheme.

DelftDashboard's Tropical Cyclone Toolbox, which computes the wind field and pressure drop generated by a cyclone, was used to simulate the ocean water levels [17]. This tool is based on the wind enhanced scheme [19]. The wind field is generated based on the analytical cyclone model of Holland [20] that was further improved by introducing asymmetry.

For a particular cyclone it is necessary to define its trajectory and associated time steps, maximum wind speed $\left(\mathrm{V}_{\max }\right)$, maximum radius wind speed $\left(\mathrm{R}_{\max }\right)$, and pressure drop $\left(\mathrm{P}_{\text {drop }}\right)$. The intensity or maximum wind speed is defined as the system's maximum sustained winds. The radius of maximum winds is characterized as the distance from the center of the tropical cyclone to the location of the cyclone's maximum winds. In well-developed hurricanes the radius is found in the inner eyewall, while in subtropical systems the radius very frequently occurs far away from the center. Lastly, the pressure drop represents the difference between the ambient and central pressures of a tropical system. The space-varying wind and pressure on a polar cyclone-following grid is added to the background wind input, which is then interpolated and combined in and around the cyclone [17].

\subsection{Generation of Storms}

A hazard assessment of the effect of an exacerbation of the typically observed storms in the region was performed. Considering results from changes in the trajectories of the various historical storms, the analysis of the coast's response to storminess was assessed using the execution of different hypothetical scenarios. Several simulations under conditions of uncertainty were generated, recurring to form an ensemble of simulations. When dealing with natural systems, like weather and climatic conditions, they should be treated as a statistical system rather than a deterministic one. Since the true state of the atmosphere can only be approximately observed, a statistical mean of a set of model forecasts, starting from slightly different initial states, reduces the impact of initial data uncertainties on the final forecast [21].

The studied factors that were influential in the accuracy of the prediction of the effects of a tropical cyclone were the cyclone's position, its intensity, the radius of maximum winds, and its atmospheric pressure drop. Geographical shifts were applied to the "normal" trajectories of the cyclones while simultaneously varying the meteorological conditions. The Asoftech Automation Macro Recorder [22] was utilized for the process of creating a randomized tropical cyclone and repeating it for any desired number of times. With its 'Schedule' feature, the macro was set to run at a pre-defined time and to repeat indefinitely. Certain reasonable limits were adopted for the values of the variables (latitude, longitude, $V_{\max }, R_{\max }$, and $P_{\text {drop }}$ ) based on observed values in the case study region. The variables were then 
randomized according to the limits so that the ensemble members displayed correlations between each other, but at the same time the simulations resulted in different possible outcomes.

The first established variable was the tropical cyclones' track positions; that is, how their longitude and latitude progress throughout the given time period. Normally, as tropical cyclones travel westward, they tend to curve poleward with a continued period of transitioning from tropical systems to extratropical. At the beginning of the season the delayed warming of the oceans tends to force the location of the transition northward, since the critical threshold for tropical development is pushed northward. As the season progresses, after the month of August, the climatologically favored region for baroclinic development expands southward [12]. It is at this point that the trailing ends of tropical cyclones become the most threatening in Portugal's case. In order to imitate trajectories that reach Western Europe, specifically the northern Portuguese coast, the first imposed limitation was that the latitude not surpass a certain limit, selected as $45^{\circ} \mathrm{N}$. Contrary to the case study seen in the paper by Gomes et al. [14], the peak was in the latitudinal direction because during the high "hurricane season", occurring between August and October, the transition occurs between $40^{\circ} \mathrm{N}$ and $50^{\circ} \mathrm{N}$ [12]. The cyclones' paths were selected to begin at a random value between $36.5^{\circ} \mathrm{N}$ and $44.8^{\circ} \mathrm{N}$ latitude (Figure 2). The values were set to increase in random intervals between $0.1^{\circ}$ and $0.3^{\circ}$ if the point's latitude occurred before reaching the turning point. At this point, the trajectory was forced southward so as to hit the Iberian Peninsula. If the point reached the established latitudinal peak at $45^{\circ} \mathrm{N}$, the values were set to subsequently decrease in random intervals between $0.1^{\circ}$ and $0.5^{\circ}$. The very small variance in the paths' latitudes was to ensure a somewhat direct, or "straight", cyclonic trajectory towards the coast, similar to what is usually witnessed in this region.

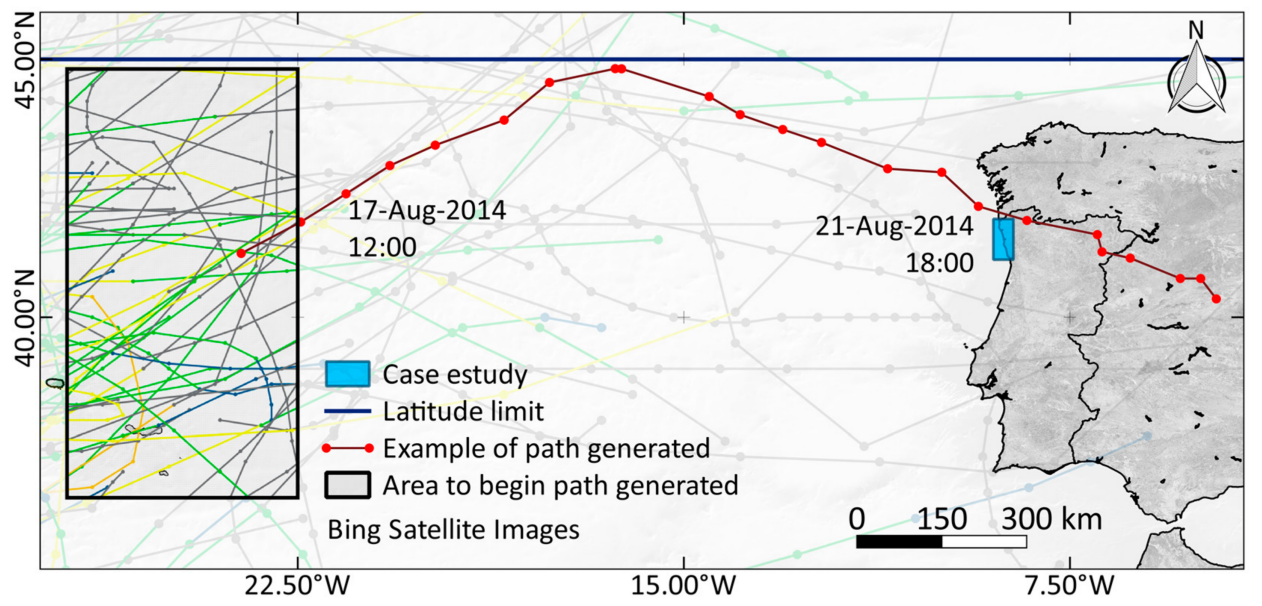

Figure 2. Ensemble simulations' latitudinal and longitudinal considerations.

For the paths' longitudinal values, the tropical cyclone trajectories were set to begin at a random value between $27.0^{\circ} \mathrm{W}$ and $22.5^{\circ} \mathrm{W}$ longitude. The following points were then set to increase in random increments between $0.5^{\circ}$ and $1.0^{\circ}$. Again, the relatively small variance was adopted in order to keep the paths of the tropical cyclones as straight as possible.

With the combination of the longitude and latitude origins, the beginning of the simulated trajectories was established in the region of the Portuguese Azores Islands. This is because it is usually at this point that a lot of the tropical cyclones occurring in the area travel towards Western Europe. There are a variety of different tropical cyclone paths that pass through this point, including tropical cyclones that reach the United States' coast and continue to gain strength and travel across the Atlantic Ocean. In contrast, there are tropical cyclones that begin in the lower tropics and curve poleward in the mid-Atlantic very early in their development. The different types of paths are portrayed in Figure 3 [15]. It was decided to simulate the small part of the tropical cyclone that would 
reach the Portuguese coast-their tail-ends. It seemed as though this was the component that these tropical cyclones, as a group, had in common.

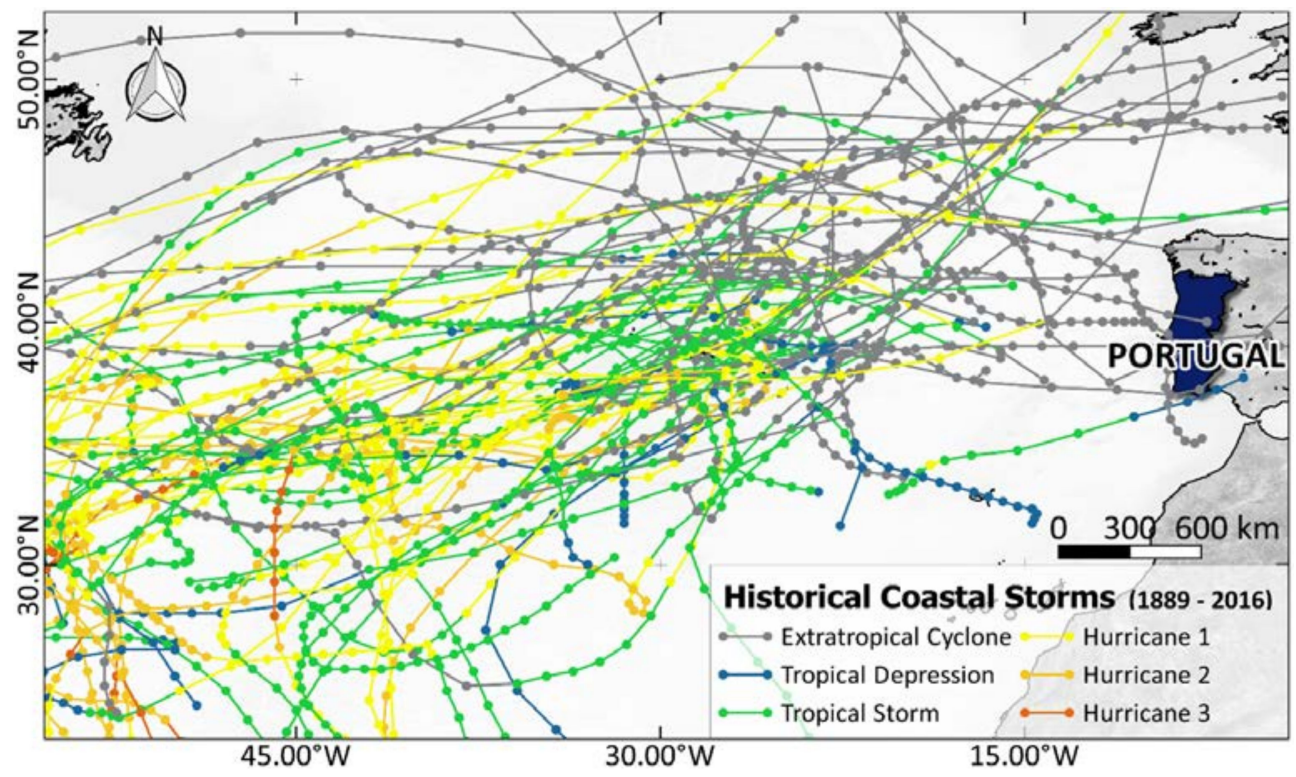

Figure 3. Mid-Atlantic historic tropical cyclones [15].

Another adopted randomized variable was the maximum sustained wind velocity, $\mathrm{V}_{\max }$. In the region of the Azores Islands, this variable was selected to begin with a random value between 55.0 and 98.0 knots (101.86 and $181.50 \mathrm{~km} / \mathrm{h}$ ), in an attempt to span the various values historically recorded in that area. Because the tropical cyclones that approach the Portuguese coast are typically already transitioning extratropical cyclones with very low intensities, the main particularity to apply to the intensity's definition was that the cyclones' $V_{\max }$ values do not fall below 30 knots $(55.56 \mathrm{~km} / \mathrm{h})$. The decrease in $\mathrm{V}_{\max }$ values was carefully controlled to avoid wind speeds reaching values below 25 knots $(46.30 \mathrm{~km} / \mathrm{h})$, which would lead to the non-generation of the wind field-a limitation that is assumed in the software. This would be equivalent to having a simulation with just the tidal influences acting upon the study area, rendering the simulation useless for our purposes. The analysis undertaken in these ensemble simulations was the coast's vulnerability to coastal storms; specifically, coastal storms that could truly impact the shoreline. Because of this, each point's intensity in the storm trajectory was set to decrease in random intervals between 1.0 and $1.5 \mathrm{knots}(1.85$ and $2.78 \mathrm{~km} / \mathrm{h})$ if the previous point was greater than or equal to 30 knots $(55.56 \mathrm{~km} / \mathrm{h})$. If the value decreased so much that it reached $30 \mathrm{knots}(55.56 \mathrm{~km} / \mathrm{h})$, the following point was set to decrease in smaller random intervals between 0.5 and 1.0 knots $(0.93$ and $1.85 \mathrm{~km} / \mathrm{h})$.

The radius of maximum winds was a factor of utmost difficulty to define, especially in this specific region. In the middle of the Atlantic Ocean there are instances in which the tropical systems can sustain wind speeds of up to 95 knots $(175.94 \mathrm{~km} / \mathrm{h})$, corresponding to a Category 2 hurricane. However, there can also be tropical systems with very weak wind speeds, not even reaching 30 knots $(55.56 \mathrm{~km} / \mathrm{h})$. Because the intensity of storms is so varied in this area, specifically around the Azores Islands, the initial attributed $R_{\max }$ of the tropical cyclone path also needs to greatly vary. A tropical system with a small $R_{\max }$ produces much more disastrous effects versus the same tropical system with a much larger $R_{\max }$. The $R_{\max }$ for the ensemble members was set to begin at any random value between 50 and 125 nautical miles ( 92.6 and $231.5 \mathrm{~km}$ ). It was then set to increase in random intervals between 0.5 and 1.0 nautical miles $(0.93$ and $1.85 \mathrm{~km})$. Because of this variation, different classes of tropical systems were expected to be observed.

Last of all, the pressure drop, $\mathrm{P}_{\text {drop, }}$, was selected to begin with a random value between 2500 and 6000 Pascal. The subsequent points were then set to decrease in random intervals between 
100 and 500 Pascal, while avoiding the pressure drop reaching values below 1000 Pascal. If the $P_{\text {drop }}$ decreased too much, the simulation was set to consider 2200 Pascal as the value instead, and the process would resume from that value. This way, the value attributed at the beginning of the trajectory would be greatly varied, capable of reaching up to 6000 Pascal, but when getting closer to the Portuguese coast the value would never exceed the 2000 Pascal mark. With all these randomized variables, the different tropical cyclone outputs then produced very different water level results, ideal for the purposes of the ensemble of simulations. The randomized parameters, which were qualitatively consistent with the few available historical records, were used to generate storm wind fields according the algorithm implemented in DelftDashboard [20]. This simplified approach was adopted instead of a sounder storm generation methodology (e.g., [23,24]).

Because these natural systems are of such a chaotic nature, nonlinear errors are common and therefore the application of the ensemble of simulations can be of great value. The change in the initial properties of the cyclones can significantly influence the results, so a statistical mean of a set of model forecast can reduce the impact of the initial data uncertainties on the final result. The different outputs should produce significant differences in solutions, whose distribution should match the actual frequency of occurrence.

In the following stage, the numerical results are processed and analyzed, and the results of the water surface elevation are assessed in order to examine the envelope of the water level; that is, the maximum storm surge height at predefined locations of the coastal zone for a given storm. This parameter can be easily linked to potential areas that could be affected by wave-overtopping, flooding, and coastal erosion. More precisely, for predefined locations, the Maximum Envelope of Water (MEOW) was obtained for a particular storm of a given category. Afterwards, the Maximum of the MEOWs (MOM) was selected for each storm category, among all the maximum storm surge heights of all simulated storms of the same category [25]. There is one MOM per storm category for each location; thus, once the maximum envelope of water levels for a given storm category (MOM) is found, it is possible to assess the storm impact for the study area based on this variable. The obtained results are very important in order to predict the potential consequences of future storm events and to produce useful information that could be utilized in the design of emergency plans. In this case study, there was very little hourly tide gauge information available, and any information that was available had no coincident records with historical events storms. Consulting the UHSLC database [26] there is only one observation station with available quality research data. This station is located in the city of Cascais, Portugal, which is much too far from the area of interest. Because previous applications of DelftDashboard and Delft3D have shown successful results elsewhere (e.g., Gomes et al. work [14]), following careful consideration these results were also deemed sufficiently accurate. The vulnerability of the region to storminess is assessed based on the simulations of the recreated storms.

\subsection{Historical Storms}

No historical record of hurricanes was found in this area of interest. In this region, only tropical storms and tropical depressions have tended to hit the coast. Since the chosen area is usually reached by the trailing end of these tropical systems, tropical storms and depressions are more frequent occurrences. Due to the limitations of the DelftDashboard's wind field generator tool, most of the time, tropical depressions cannot be recreated in this setting. Unlike in the US case study [14], a couple of the identified tropical depressions were effectively simulated given that a tropical depression can sustain winds of up to 33 knots $(61.12 \mathrm{~km} / \mathrm{h})$, which is still within the possible parameters for the creation of a storm wind field.

In this location, the tropical systems do not follow a normal pattern, contrary to the case study area on the other side of the Atlantic Ocean. There are tropical systems that proceed more northward affecting England and Ireland, while others curve poleward much earlier in their development and the lean eastward, affecting the Azores Island and consequently traveling towards the Iberian Peninsula. 
As shown in Table 1, in the vicinity of the Portuguese coast, of the 22 identified storms there were 9 identified occurrences of tropical depressions, 11 identified occurrences of tropical storms and only 2 identified occurrences of cyclones (categorized as Category 1). More intense events, particularly tropical cyclones of higher categories, were not registered. Thus, between 1842 and 2016, for the Portuguese territory, a tropical depression had a probability of occurrence of $50.0 \%$, a tropical storm had a probability of $40.9 \%$, and a tropical cyclone had a probability of $9.1 \%$.

Table 1. History of coastal storms in the vicinity of the Portuguese northwestern coast (1842-2016), [15,16].

\begin{tabular}{|c|c|c|c|c|}
\hline Name & Year & Start Date & End Date & Velocity $(\mathrm{km} / \mathrm{h})$ \\
\hline \multicolumn{5}{|c|}{ Tropical Depression: $<62$} \\
\hline Dolly & 1953 & Sep. 8 & Sep. 17 & 46 \\
\hline Carol & 1965 & Sep. 16 & Oct. 1 & 46 \\
\hline Arlene & 1987 & Aug. 8 & Aug. 28 & 19 \\
\hline Bob & 1991 & Aug. 16 & Aug. 29 & 19 \\
\hline Frances & 1992 & Oct. 22 & Oct. 30 & 54 \\
\hline Jeanne & 1998 & Sep. 21 & Oct. 4 & 54 \\
\hline Vince & 2005 & Oct. 8 & Oct. 11 & 54 \\
\hline Gordon & 2012 & Aug. 15 & Aug. 21 & 56 \\
\hline Rafael & 2012 & Oct. 12 & Oct. 17 & 56 \\
\hline \multicolumn{5}{|c|}{ Tropical Storm: 62 to 118} \\
\hline Vince & 1842 & Nov. 26 & Nov. 30 & 93 \\
\hline Not named & 1892 & Sep. 3 & Sep. 7 & 74 \\
\hline Not named & 1952 & Sep. 8 & Sep. 12 & 65 \\
\hline Lois & 1966 & Nov. 4 & Nov. 14 & 81 \\
\hline Chloe & 1967 & Sep. 5 & Sep. 21 & 81 \\
\hline Irene & 1981 & Sep. 21 & Oct. 3 & 81 \\
\hline Ivan & 1998 & Sep. 19 & Sep. 27 & 81 \\
\hline Gordon & 2006 & Sep. 10 & Sep. 24 & 102 \\
\hline Grace & 2009 & Sep. 27 & Oct. 6 & 102 \\
\hline Melissa & 2013 & Nov. 18 & Nov. 21 & 65 \\
\hline Joaquin & 2015 & Sept. 28 & Oct. 7 & 65 \\
\hline \multicolumn{5}{|c|}{ Cyclone (category 1): 119 to 153} \\
\hline Not named & 1941 & Feb. 13 & Feb. 15 & 130 \\
\hline Xynthia & 2010 & Feb. 26 & Mar. 3 & 149 \\
\hline
\end{tabular}

\subsection{Hydrodynamic Model of the Portuguese Coastal Zone}

One domain was considered for the Portuguese coastal region. This domain was discretized (Figure 4) with a high spatial resolution grid with $329 \times 232$ grid cells (cell size approximately $0.03^{\circ}$ ).

The hydrodynamic domains were geo-referenced using the WGS 84 (World Geodetic System) coordinate system. The bathymetry was based on a continuous terrain model for ocean and land with a spatial resolution of 30 arc-seconds from the General Bathymetric Chart of the Oceans, GEBCO_08 Grid [27]. The open boundary conditions and initial conditions were given by TPXO 7.2, a version of the global model of ocean tides [28]. The storm wind fields were generated using recorded data of atmospheric pressure, wind speed, storm trajectory, and velocity (e.g., Tropical Depression Rafael which occurred in 2012, represented in Figure 5). Using data available in the Tropical Atlantic's Best Track Data database, simulations for the Portuguese coast ran using storm track information that included the latitude and longitude of the storm's eye, the maximum sustained 1 min wind speed, the pressure drop, and the radius of maximum winds. 


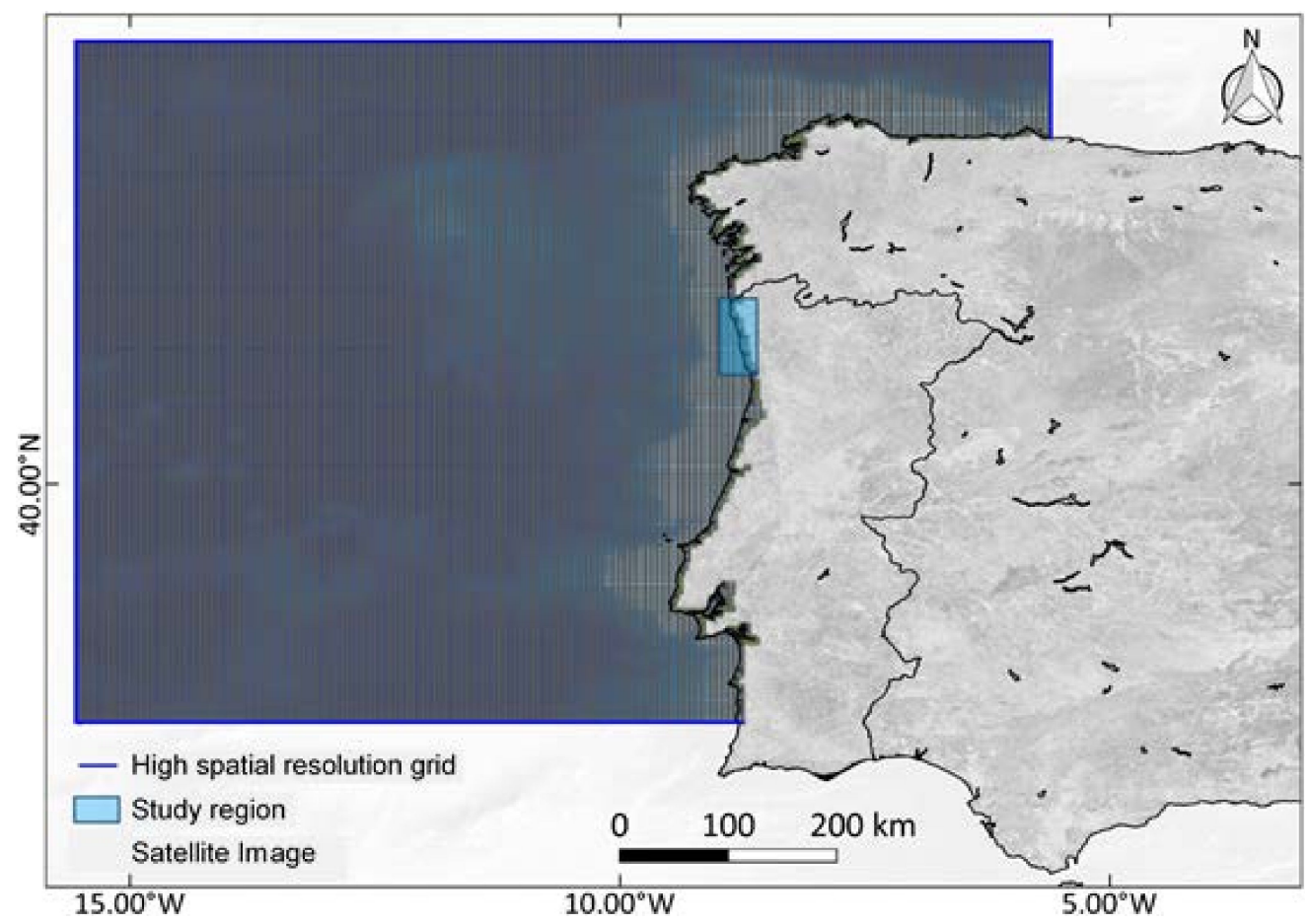

Figure 4. Grids generated for the simulation of storm scenarios on the NW Portuguese coast.

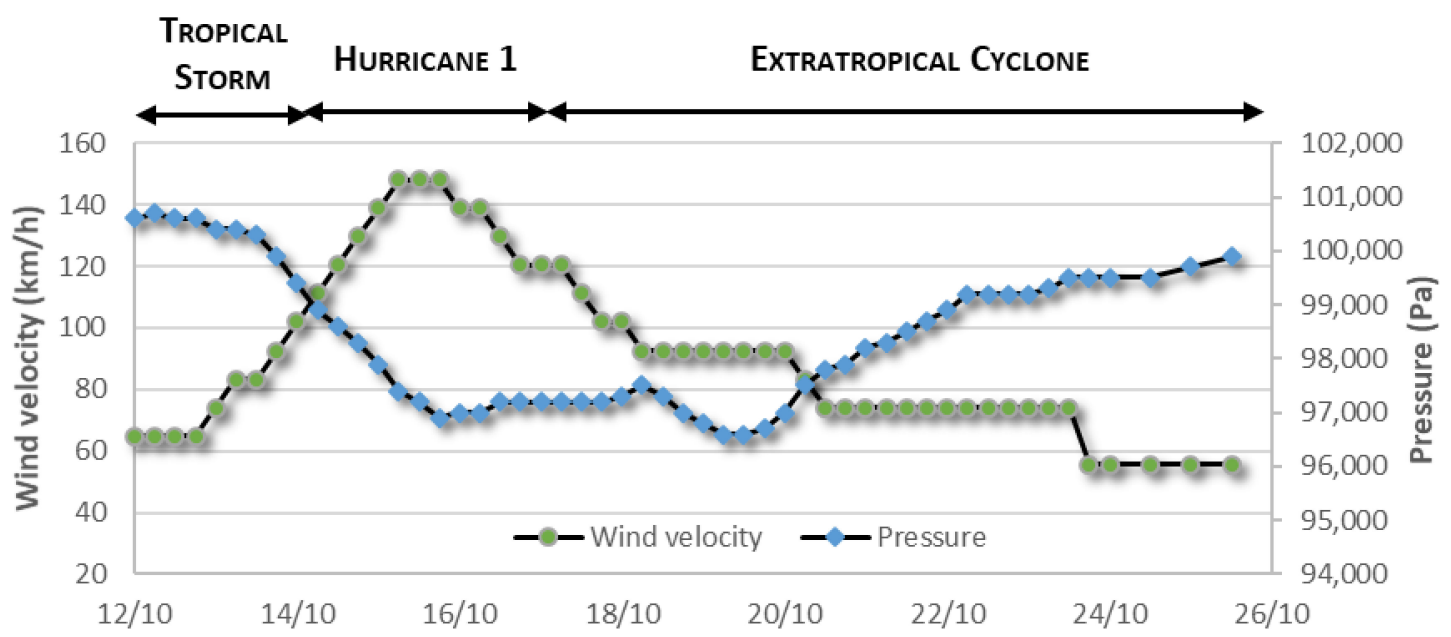

Figure 5. Rafael 2012 [15]: atmospheric pressure and wind velocity in the eye of the storm.

\section{Results and Discussion}

Delft3D models ran with simulation times between 4 and 20 days, and each simulation lasted from about 40-60 min. The simulations were carried out with the use of an Intel Core i7-4700 MQ, $2.40 \mathrm{GHz}$ processor. When developing the storm wind field in DelftDashboard, if the maximum velocity (wind speed) is below $46.2 \mathrm{~km} / \mathrm{h}$, the generated wind field will correspond to null velocities at that time step, and time steps thereafter. Because of this, tropical depressions (a very common occurrence in the case study region) were eliminated. Tropical Depression Dolly (1953), Carol (1965), Arlene (1987), and Bob (1991) each produced wind speeds below 25 knots (46.30 km/h), therefore were unable to be recreated; however, both Tropical Depression Jeanne (1998) and Rafael (2012) struck the Iberian Peninsula's coast with a maximum sustained wind velocity of 30 knots $(55.56 \mathrm{~km} / \mathrm{h})$. Because the velocities were above the 25 knot lower limit it was possible to recreate these storms. The tropical storms that occurred much too far away from the Portuguese coast were Lois (1966), 
Ivan (1998), Grace (2009), and Melissa (2013). As a result, the tropical storms that were simulated were Chloe (1967), Irene (1981), Frances (1992), Jeanne (1998), Gordon (2006), and Rafael (2012).

Figure 6a shows the storm wind field when approaching the Iberian Peninsula (on a larger scale), and Figure $6 \mathrm{~b}$ shows the pressure field when the center of the storm is near the central region of Portugal. Knowing the location of our study region, we can obtain the maximum level reached in the exact position, as shown in Figure $6 \mathrm{c}$ for Tropical Depression Rafael. The resulting predicted surge values (Table 2) were much smaller when compared to the results seen for The Battery, New York [14]. The maximum storm surge observed in this case was during Tropical Storm Gordon's 2006 cyclone, which produced a surge of $0.53 \mathrm{~m}$. The storm surges mostly varied between 0.01 and $0.60 \mathrm{~m}$ in height. The simulated water level values were then compared to identical situations which did not consider the wind's effect, taking into account merely the tidal influences. The difference between the two is the referred storm surge.

Table 2. Simulated water level values for the location of the river Douro estuary.

\begin{tabular}{ccccc}
\hline Name & Year & Simulated Water Level $(\mathbf{m})$ & Without Wind Field $(\mathbf{m})$ & Surge $(\mathbf{m})$ \\
\hline Irene & 1981 & 1.32 & 1.31 & 0.01 \\
Frances & 1992 & 1.45 & 1.28 & 0.17 \\
Jeanne & 1998 & 1.43 & 1.39 & 0.04 \\
Gordon & 2006 & 2.07 & 1.54 & 0.53 \\
Rafael & 2012 & 1.07 & 1.04 & 0.03 \\
\hline
\end{tabular}

For the ensemble simulations phase, a sequence of 209 simulations were randomly created. Considering a small area within the grid corresponding to the area of interest (between the Douro and Lima estuaries), the maximum water level was obtained for all ensemble member results for that specific area. The graph in Figure 7 displays the results for the ensemble simulations carried out for the region of the Portuguese northwestern coast. Of the 209 ensemble members, 197 members resulted in a water level of less than $2 \mathrm{~m}, 152$ members resulted in a water level of less than $1.5 \mathrm{~m}, 91$ members resulted in a water level of less than $1.3 \mathrm{~m}$, and 25 members resulted in a simulated water level of less than $1.2 \mathrm{~m}$. This means that the simulated water level limits of $2.0,1.5,1.3$, and $1.2 \mathrm{~m}$ covered $94.26 \%$, $72.73 \%, 43.54 \%$, and $11.96 \%$ of the total ensemble members, respectively.

For situations in which the randomly created tropical cyclone trajectory did not reach the region the resulting water level was $1.2 \mathrm{~m}$, resulting from tidal water levels associated with the tide characteristics adopted in the ensemble of simulations. Seventeen of the 209 ensemble members created were unaffected by the tropical cyclone simulations, corresponding to $8.13 \%$ of the total.

The tropical cyclone with the worst simulation scenario outcome corresponds to the simulation that resulted in the highest predicted sea level. In this case, the storm track hits the northwestern corner of the Iberian Peninsula, resulting in a maximum sea level of $2.3 \mathrm{~m}$ on August 22, 2014 at 14:00 p.m. in the area encompassing northern Portugal. Because the trajectory's points are only recorded every six hours, the closest time step to the maximum predicted sea level found at 14:00 p.m. was the 12:00 p.m. time step, two hours before the defined storm variables. At the 12:00 p.m. time step the following parameters were randomly generated: a latitude of $43.4^{\circ} \mathrm{N}$, longitude of $9.2^{\circ} \mathrm{W}$, $\mathrm{V}_{\max }$ velocity of 68.1 knots $(126.12 \mathrm{~km} / \mathrm{h}), \mathrm{R}_{\max }$ of about 80.2 nautical miles $(148.53 \mathrm{~km})$, and a $\mathrm{P}_{\text {drop }}$ of about 2200 Pascal.

The resulting ensemble members had 12 trajectories of tropical cyclones that surpassed $2 \mathrm{~m}$ in height; that is, $5.74 \%$ of the total. Considering the initial historical conditions observed for these ensemble members, the most exacerbated situation was only able to produce a sea level height of $2.3 \mathrm{~m}$. 

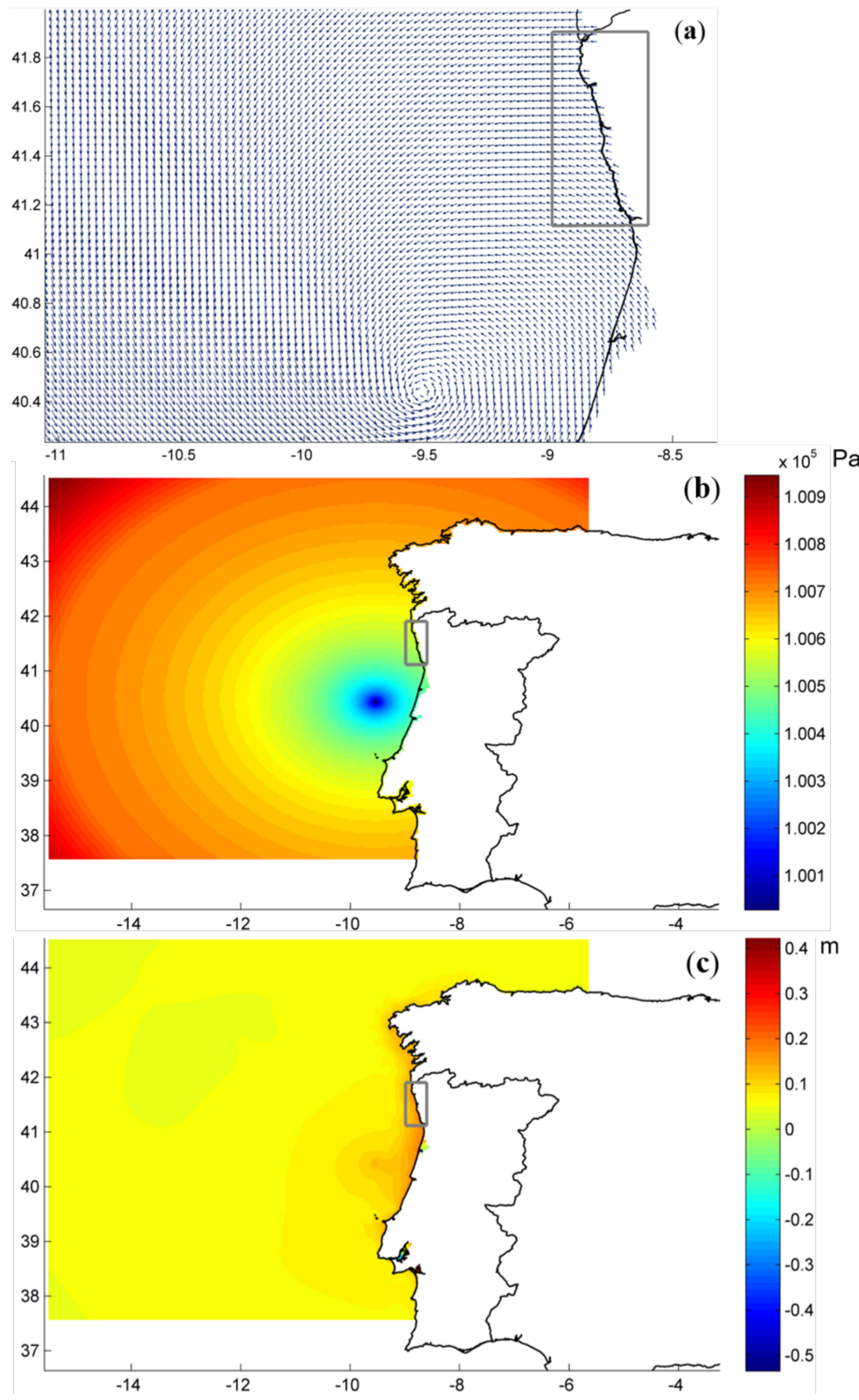

Figure 6. Example of coastal storm simulation results in the Iberian domain (World Geodetic System (WGS) 84 coordinate system). Rafael [15], on 26 October 2012 at 04:00 a.m.: (a) Wind field (zoom); (b) Atmospheric pressure in Pa; (c) Storm surge in meters. 


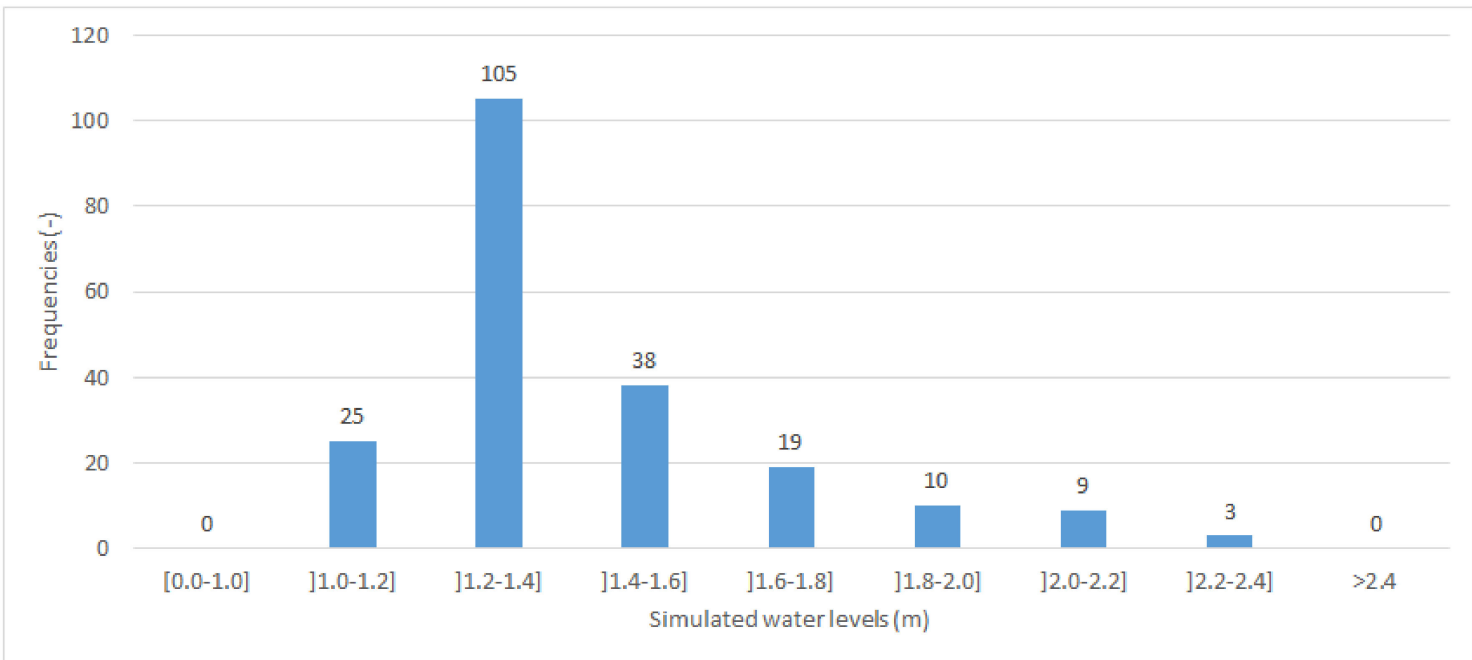

Figure 7. Ensemble simulations' results-water surface elevation frequencies.

The application of an ensemble of simulations for this study area is of great practical use. Due to the serious lack of information available in this field, this type of work becomes very valuable in terms of characterization of extreme events that affect the coast. The resulting MOMs (maximum sea level expected for each category of storm) can be indicators of the region's susceptibility to storm surges. The resulting maximum water envelope for each of the ensemble simulations (MEOWs) are shown below in Table 3.

Table 3. Ensemble's maximum of the Maximum Envelopes of Water (MEOWs) (maximum sea level expected for each category of storm (MOMs)).

\begin{tabular}{ccc}
\hline Category & No. of Occurrences & MOM $(\mathbf{m})$ \\
\hline Tropical Cyclone & 3 & 2.3 \\
Tropical Storm & 177 & 2.3 \\
Tropical Depression & 29 & 1.2 \\
\hline
\end{tabular}

\section{Conclusions}

In terms of ensemble simulations for the studied region according the described analysis, there were 3 hurricanes (all Category 1 hurricanes), 177 tropical storms, and 29 tropical depressions produced. As expected, the most commonly observed occurrences in this region are tropical depressions and tropical storms with relatively low sustained winds. A tropical storm is able to sustain winds from $62-118 \mathrm{~km} / \mathrm{h}$. Contrary to what was observed in the few records available, there was a greater amount of tropical storms observed and even a few Category 1 hurricanes among the 209 randomized storms that were generated. With the intensification of typically observed results in this study area, $37.29 \%$ of all the ensemble tropical storms experienced wind speeds of $90 \mathrm{~km} / \mathrm{h}$ or higher. The Maximum of the MEOW for the three simulated hurricanes was $2.3 \mathrm{~m}$. For the tropical storm category, the maximum sea level for the MEOWs was $2.3 \mathrm{~m}$ and for the tropical depression category the maximum sea level for the MEOWs produced a maximum of $1.2 \mathrm{~m}$. The tropical depressions, unlike in the NY/NJ area [14], did directly strike the coast.

Several tropical storms were simulated; however, there are no historical data records available for this work in order to be able to compare the obtained results. It is important to continue research in this area because tropical storms in the region are a growing issue. Even for winter storms (a more common occurrence in this region), the available data are scarce. Given the limited information available in regions such as the northwestern coast of Portugal, this kind of forecasting proves to be significant for the estimation of storm impacts. The results are a valuable contribution to our ability to estimate storm 
water levels for each storm category, and can be used to support planning and management of this coastal zone and to assist in the preparation of emergency plans. With the use of computer modeling of water levels, studies on coastal adaptations to reduce future flooding should explore the impact of protection measures such as walls, wetlands, storm surge barriers, sand dunes, and changes in the depths of shipping channels.

The results obtained in this work serve as an important contribution for further use in studies to assess the short-term evolution of the coasts, particularly if there is an increase in the frequency or intensity of hurricanes.

Author Contributions: For this research, M.P.G. contributed to the numerical simulations, the input data, software validation and results interpretation; L.S. contributed to data acquisition, performed the inventory of historic tropical cyclones, contributed to numerical simulations and data analyses; J.L.P. provided material, contributed to numerical simulations, interpreted and validated numerical results; J.S.A.D.C. conceived the manuscript, contributed to interpret and validate numerical results, reviewed and supervised the manuscript. All authors contributed to design figures and write the manuscript.

Funding: Lara Santos was partially founded by the Foundation for Science and Technology of Portugal.

Conflicts of Interest: The authors declare no conflicts of interest.

\section{References}

1. IPCC. Climate Change 2014: Synthesis Report; Contribution of Working Groups I, II and III to the Fifth Assessment Report of the Intergovernmental Panel on Climate Change; Core Writing Team, Pachauri, R.K., Meyer, L.A., Eds.; IPCC: Geneva, Switzerland, 2014; ISBN 978-92-9169-143-2.

2. Miranda, P.M.; Coelho, F.E.; Tomé, A.R.; Valente, M.A.; Carvalho, A.; Pires, C.; Ramalho, C. Chapter 2-20th Century Portuguese Climate and Climate Scenarios. In Climate Change in Portugal: Scenarios Impacts and Adaptation Measures (SLAM Project); Santos, F.D., Forbes, K., Moita, R., Eds.; Gradiva: Lisbon, Portugal, 2002; pp. 23-83.

3. Pethick, J.; Orford, J.D. Rapid rise in effective sea-level in southwest Bangladesh: Its causes and contemporary rates. Glob. Planet. Chang. 2013, 111, 237-245. [CrossRef]

4. Sousa, M.C.; Vaz, N.; Alvarez, I.; Gomez-Gesteira, M.; Dias, J.M. Influence of the Minho River plume on the Rias Baixas (NW of the Iberian Peninsula). J. Mar. Syst. 2014, 139, 248-260. [CrossRef]

5. Dinis, J.L.; Tavares, A.O. Susceptibility geomorphology of tsunamis in the Portuguese west coast. In Proceeding of the III Congress on Planning and Management of Coastal Areas of the Portuguese-Speaking Countries, Maputo, Mozambique, 5-8 October 2005; pp. 1-17. (In Portuguese)

6. Loureiro, E.; Granja, H.; Pinho, J.L.S. Morphodynamics of the Cávado Estuary Inlet (Nw Portugal); International Coastal Symposium: Höfn, Iceland, 2005.

7. Granja, H.; Pinho, J.L.S. Coastal defence in NW Portugal: The improbable victory. In The Pitfalls of Shoreline Stabilization (Coastal Research Library); Cooper, J., Pilkey, H., Eds.; Springer: New York, NY, USA, 2012; Volume 3, pp. 251-266.

8. Wind and Weather Statistic Porto-Windfinder. Available online: http://www.windfinder.com/ windstatistics/porto (accessed on 29 September 2014).

9. Silva, D.; Bento, A.R.; Martinho, P.; Soares, C.G. High resolution local wave energy modelling in the Iberian Peninsula. Energy 2015, 91, 1099-1112. [CrossRef]

10. COMET. Meteorology Education and Training-Resource Description: Wave Life Cycle II: Propagation and Dispersion. Available online: https:/ / www.meted.ucar.edu/training_module.php?id=188\#.VBBNI_ldV9p (accessed on 13 February 2014).

11. CCA—Centre for Climate Adaptation. Climate Change-Portugal—Climatechangepost.com. Available online: http://www.climateadaptation.eu/portugal/climate-change/ (accessed on 9 September 2014).

12. Hart, R.E.; Evans, J.L. A climatology of the extratropical transition of Atlantic tropical cyclones. J. Clim. 2001, 14, 546-564. [CrossRef]

13. Nott, J. Tropical cyclones and the evolution of the sedimentary coast of Northern Australia. J. Coast. Res. 2006, 22, 49-62. [CrossRef]

14. Gomes, M.P.; Pinho, J.L.; Carmo, J.S.A.; Santos, L. Hazard Assessment of storm events for The Battery, New York. Ocean Coast. Manag. 2015, 118, 22-31. [CrossRef] 
15. Historical Hurricane Tracks-NOAA's Office for Coastal Management. Available online: https:/ / coast.noaa. gov/hurricanes/ (accessed on 19 March 2017).

16. Unisys Weather-Hurricane/Tropical Data. Available online: http://weather.unisys.com/hurricane/index. php (accessed on 20 March 2017).

17. Deltares. User Manual Delft3D-FLOW. Hydro-Morphodynamics, Version: 3.15; Deltares: Delft, The Netherlands, 2011.

18. Deltares. DelftDashboard-OpenEarth—Deltares Public Wiki. 2017. Available online: https:/ / publicwiki. deltares.nl/display/DDB/Delft+Dashboard (accessed on 24 July 2017).

19. Deltares. Wind Enhanced Scheme (WES) for Cyclone Modelling. User Manual Version 3.00; Deltares: Delft, The Netherlands, 2009.

20. Holland, G.J. An analytic model of the wind pressure profiles in hurricanes. Mon. Weather Rev. 1980, 108, 1212-1218. [CrossRef]

21. Zhang, Z.; Krishnamurti, T. Ensemble forecasting of hurricane tracks. Bull. Am. Meterol. Soc. 1997, 78, $2785-2795$. [CrossRef]

22. Mouse Keyboard Macro Recorder-Automation Software. Available online: http://www.asoftech.com/ata/ (accessed on 30 March 2014).

23. Vickery, P.J.; Skerlj, P.F.; Twisdale, L.A. Simulation of hurricane risk in the US using empirical track model. J. Struct. Eng. 2000, 126, 1222-1237. [CrossRef]

24. Rumpf, J.; Weindl, H.; Höppe, P.; Rauch, E.; Schmidt, V. Tropical cyclone hazard assessment using model-based track simulation. Nat. Hazards 2009, 48, 383-398. [CrossRef]

25. Glahn, B.; Taylor, A.; Kurkowski, N.; Shaffer, W.A. The role of the SLOSH model in national weather service storm surge forecasting. Natl. Weather Dig. 2009, 33, 3-14.

26. Data-UHSLC. Available online: http:/ / uhslc.soest.hawaii.edu/data/faq (accessed on 29 March 2014).

27. BODC. Bathymetry Data from the GEBCO_08 Grid. Available online: https://www.gebco.net/data_and_ products/gridded_bathymetry_data/ (accessed on 29 March 2014).

28. COAS. TPXO 7.2-Global Inverse Tide Model. Available online: http://volkov.oce.orst.edu/tides/TPXO7.2.html (accessed on 10 October 2017). 